Celebes Abdimas: Jurnal Pengabdian Kepada Masyarakat

http://journal.lldikti9.id/CER/index

Vol 2, No, 2, Oktober 2020, pp 67-71

p-ISSN:2656-7938 dan e-ISSN: 2657-1870

DOI: https://doi.org/10.37541/celebesabdimas.v2i2.448

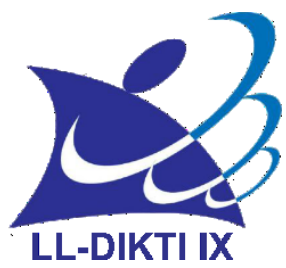

\title{
Penerapan Roll Bending Machine pada IKM Logam di Desa Tlahab Kecamatan Kledung Kabupaten Temanggung
}

\author{
Saifudin ${ }^{1}$, R Arri Widyanto ${ }^{2}$ \\ ${ }^{1}$ Mesin Otomotif, Universitas Muhammadiyah Magelang \\ Email: saifudin@ummgl.ac.id \\ 2 Teknologi Informasi, Universitas Muhammadiyah Magelang
}

\section{Artikel info}

\section{Article history:}

Received: 01-September-2020

Revised: 15-September-2020

Accepted: 11- Oktober-2020

Publish: 28-Oktober-2020

\section{Keywords:}

Roll;

Bending Machine;

IKM;
Abstract. The solutions offered to solve the problems faced by partners in this PKM scheme community service activities are: a). Equipment development, b). Production process training, c). Develop a marketing model. , using the participatory empowerment method / Participation Rural Appraisal (PRA): FGD, providing place \& facilities, training. The results of PKM are: (1) the interest and motivation of PKM partners is high enough or enthusiastic to participate in all activities provided by the PKM implementation team, (2) PKM partners have sufficient knowledge and skills to increase the quantity of products by utilizing a roll bending machine, (3) PKM partners have sufficient knowledge and skills to improve product quality.

Abstrak. Solusi yang ditawarkan untuk menyelesaikan permasalahan yang dihadapi mitra pada kegiatan pengabdian masyarakat skim PKM ini adalah: a). Pengembangan peralatan, b). Pelatihan proses produksi, c). Mengembangkan model pemasaran. , menggunakan metode pemberdayaan partisipatif / Participation Rural Apraisal (PRA): FGD, menyediakan tempat \& sarana, pelatihan. Hasil PKM adalah: (1) minat dan motivasi mitra PKM cukup tinggi atau antusias untuk mengikuti seluruh kegiatan yang diberikan oleh tim pelaksana kegiatan PKM, (2) mitra PKM telah memiliki pengetahuan dan keterampilan yang memadai untuk meningkatkan kuantitas produk dengan memanfaatkan roll bending machine, (3) mitra PKM telah memiliki pengetahuan dan keterampilan yang memadai untuk meningkatkan kualitas produk.
Coresponden author: Saifudin

Mesin Otomotif, Universitas Muhammadiyah Magelang Jl. Tidar No.21, Magersari, Magelang, Jawa Tengah Email: saifudin@ummgl.ac.id

artikel dengan akses terbuka dibawah lisensi CC BY -4.0 


\section{PENDAHULUAN}

Desa Tlahab, Kecamatan Kledung, Kabupaten Temanggung. Desa Tlahab terletak antara: 110o23'-110o46'30" Bujur Timur, 7o14'-7o32'35" Lintang Selatan (Badan Pusat Statistik, 2018) Wilayah Desa Tlahab sebagian besar merupakan dataran dengan ketinggian antara 500-1450 meter di atas permukaan air laut, dengan keadaan tanah sekitar 50\% dataran tinggi dan 50\% dataran rendah. Batas wilayah Desa Tlahab: a). Sebelah Barat: Kabupaten Wonosobo, b). Sebelah Utara: Kecamatan Bansari, c). Sebelah Timur: Kecamatan Parakan, Kecamatan Bulu, d). Sebelah Selatan: Kabupaten Magelang. Desa Tlahab pada umumnya berhawa dingin dimana suhu udara pegunungan berkisar antara 20oC-30oC. Jumlah penduduk Desa Tlahab sebanyak 3.831 jiwa yang terdiri dari 2 Dusun, 4 RW dan 21 RT dengan mata pencaharian utama pada bidang pertanian dan industri pengolahan pertanian (Badan Pusat Statistik, 2018). Komoditas utama bidang pertanian desa Tlahab adalah tembakau dan kopi. Ada 4 IKM pengolahan industri hasil pertanian tembakau dan kopi di desa tersebut (Pemerintah Daerah, 2018).

IKM BINA USAHA, milik Bapak Triyanto yang beralamat di Jl. Parakan-Wonosobo KM. 09, Desa Tlahab, Kecamatan Kledung, Kabupaten Temanggung bergerak dalam bidang industri pengelasan logam. Keberadaan IKM BINA USAHA sangat strategis dalam mendukung industri pengolahan hasil pertanian di Desa Tlahab. IKM BINA USAHA bergerak dalam bidang usaha industri pengelasan logam, mengerjakan pembuatan mesin-mesin peralatan sederhana untuk industi pengolahan hasil pertanian dan melayani perbaikan alat-alat pengolahan hasil pertanian. Mesin-mesin industri buatannya diantaranya mesin perajang tembakau, mesin pengupas kopi dan mesin sangrai kopi.

Berdasar analisis situasi yang telah dilaksanakan terhadap mitra, ditemukan beberapa permasalahan dalam aspek produksi, yaitu peralatan produksi yang dimiliki masih konvensional yang menyebabkan kapasitas produksi rendah, selain itu peralatan yang ada kurang ergonomis sehingga memunculkan ketidak nyamanan kerja para karyawannya, memunculkan keluhan yang berpengaruh pada produktifitas kerja. (Widodo, Ariyanti, \& Kurniawan, 2019). Situasi tempat usaha terlihat pada Gambar 1.
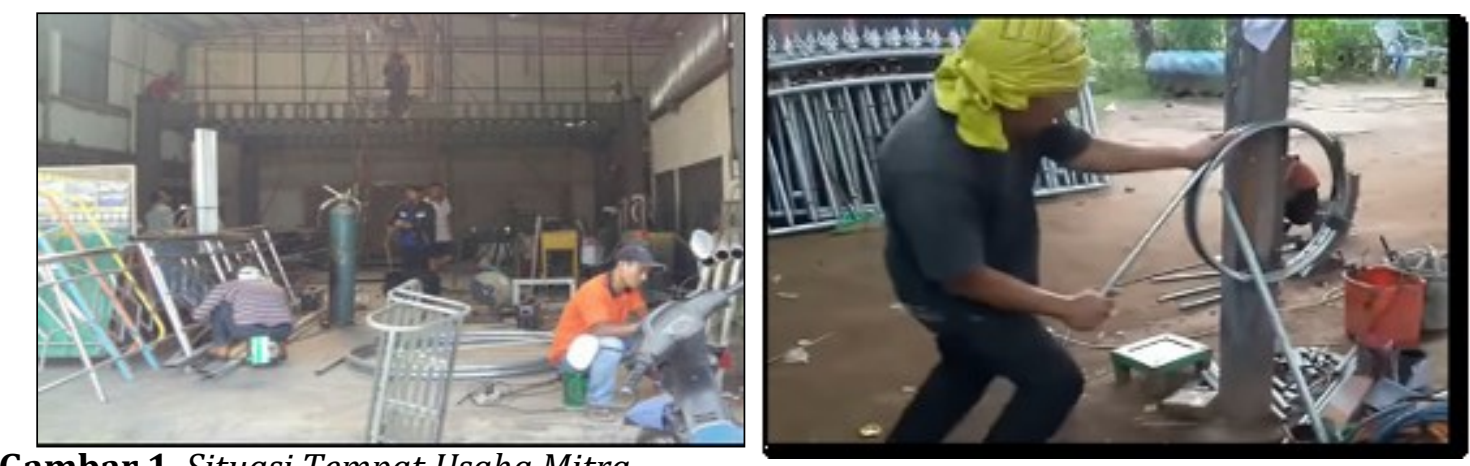

Gambar 1. Situasi Tempat Usaha Mitra

\section{METODE}

Metode yang digunakan utuk menyelesaikan permasalahan mitra yang berkaitan dengan alat produksi, menggunakan metode pemberdayaan partisipatif / Participation Rural Apraisal (PRA). Metode ini memerlukan partisipasi dari mitra, terutama berkaitan dengan informasiinformasi yang dimiliki mitra. (Zakaria, 2018). Berikut ini adalah penerapan PRA : a) Focus Group Discusion (FGD) dengan mitra untuk menentukan prioritas permasalahan, solusi dan proses pelaksanaan kegiatan untuk menyelesaikan permasalahan. b) Mitra menyediakan tempat dan sarana yang dibutuhkan oleh tim untuk melaksanakan kegiatan. c) Bersama tim, mitra terlibat dalam kegiatan transfer teknologi yang berupa penyuluhan, pelatihan pengembangan peralatan produksi, dan pendampingan pengoperasian pengoperasian peralatan. 


\section{HASIL DAN PEMBAHASAN}

a. FGD dengan mitra.

FGD adalah bisa berinteraksi dengan mitra (Kripsphianti, Setyaputri, \& Muzaki, 2019). Hasil dari FGD ini ditentukan masalah yang dikerjakan adalah pengembangan peralatan produksi. Topik ini dipilih karena permasalahan yang ada sangat kompleks dan tidak mungkin diselesaikan dalam waktu singkat, sehingga tim dan mitra menyepakati menyelesaikan permasalahanan peralatan produksi. Kegiatan FGD terlihat pada Gambar 2.

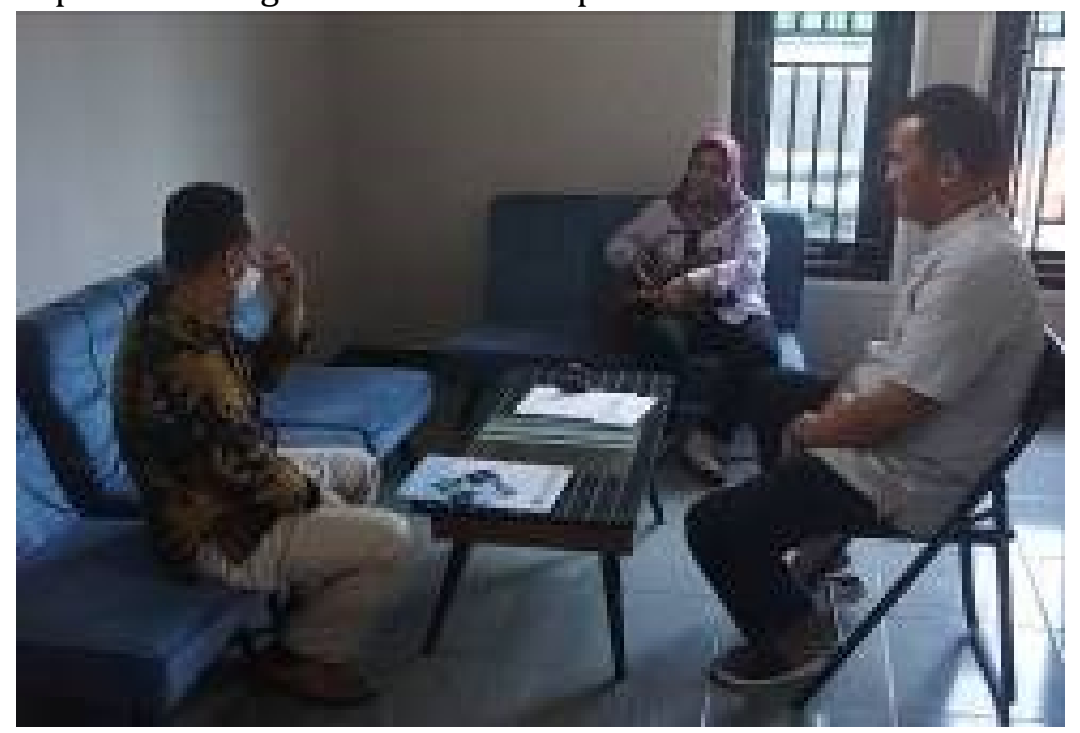

Gambar 2. FGD dengan mitra

b. Penyediaan tempat dan sarana oleh mitra.

Tempat dan saran kegitan yang disediakan cukup memadai untuk melakukan kegiatan seperti pada Gambar 3.
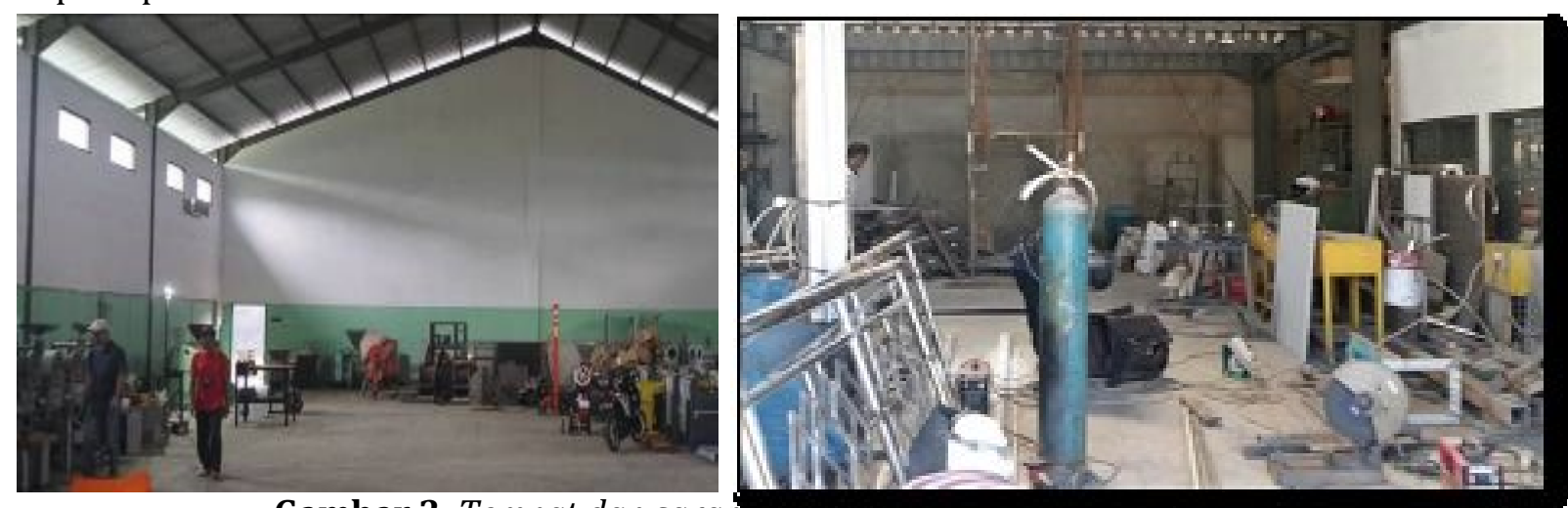

Gambar 3. Tempat dan saraña kegratan

c. Kegiatan transfer teknologi.

Kegiatan transfer teknologi bisa dilakukan dengan pemberian materi dan kuesioner (Apriliyanto, 2020). Kegiatan trasfer teknologi pada PKM ini berupa perancangan peralatan, pelatihan pengembangan peralatan produksi dan pendampingan. Alat produksi yang dikembangkan berupa roll bending machine. Teknik bending merupakan proses pembentukan logam (Prayoga, 2015). Pada IKM ini teknik bending digunakan untuk membentuk plat dan pipa yang digunakan sebagai bahan pembuatan alat-alat pertanian. Perancangan peralatan kerja menggunakan software CAD dengan hasil seperti terlihat pada Gambar 4. Software ini digunakan untuk merancang gambar secara cepat dan akurat (Atmajayani, 2018). 
70| Celebes Abdimas: Jurnal Pengabdian Kepada Masyarakat

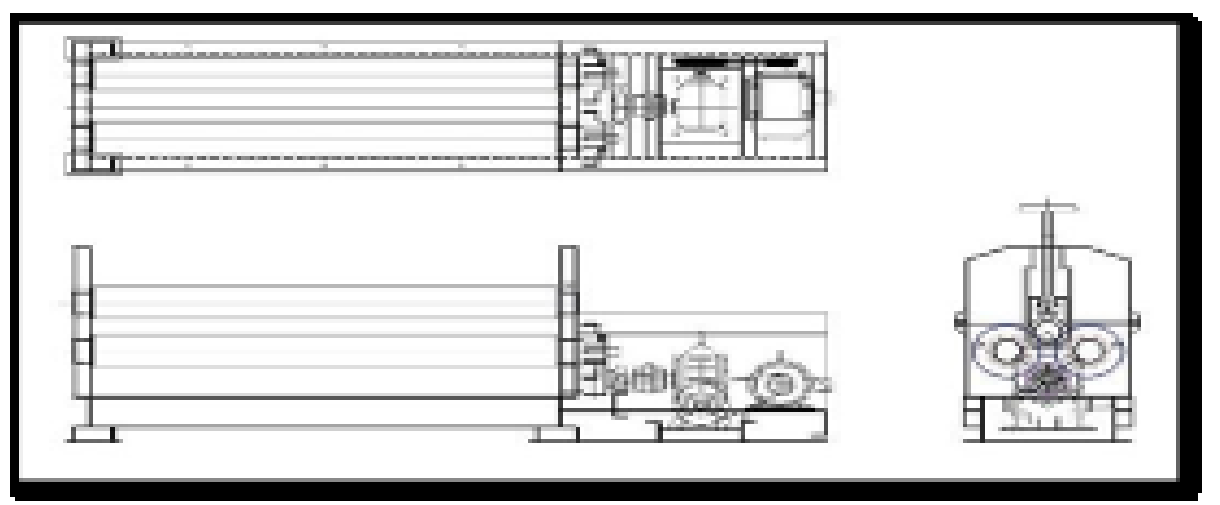

Gambar 4. Desain Roll Bending Machine

Hasil implementasi dari desain mesin roll bending, terlihat pada Gambar 5. Mesin ini bisa digun akan pada plat dengan berbagai ketebalan yang diatur naik turunya.

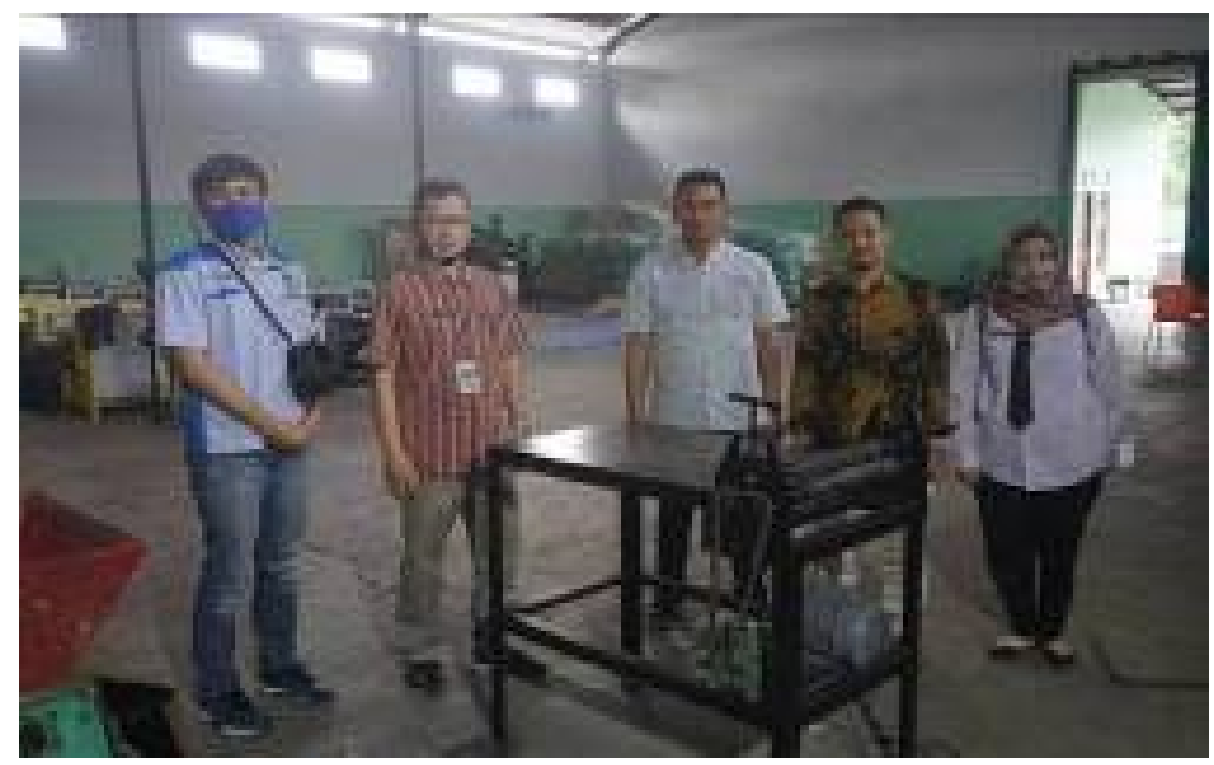

Gambar 5. Roll Bending Machine

Alat dan bahan yang digunakan untuk pembuatan mesin roll bending adalah:

1. Dinamo motor $0,5 \mathrm{HP}$.

2. Gear Box 50

3. Roda Gigi 12

4. Pully $0,5^{\prime \prime}$

5. As 2"

6. Besi profil L $5 \times 5 \mathrm{~mm}$

7. Plat $1 \mathrm{~cm}$

8. Bearing UCT / UCP 205

Prinsip kerja mesin ini menurut (Sonawan, 2014) adalah:

1. Benda kerja berupa lembaran plat dimasukkan diantara 3 buah roll.

2. Satu buah roller atas bisa diatur naik dan turun dengan menggunakan ulir.

3. Dua buah roller bawah diputar dengan roda gigi, gear box dan motor.

4. Dilengkapi pully, $V$ belt, bearing chain coupling dan cover pengaman.

5. Lebar plat yang memiliki ukuran $1800 \mathrm{~mm}$ pada bagian bawah roller di beri support. 
6. Menggunakan metal bearing bronze tebal $8 \mathrm{~mm}$.

7. Control panel lokal, untuk menggerakkan 2 Arah.

8. Salah satu sisi dilengkapi engsel untuk mengambil plat roll yang sudah jadi.

Hasil kerja dari alat ini menghasilkan plat dalam bentuk lingkaran atau $1 / 2$ lingkaran sesuai kebutuhan.

\section{SIMPULAN DAN SARAN}

Berdasarkan hasil pelaksanaan kegiatan program PKM yang telah dilaksanakan oleh Tim Pelaksana PKM, maka dapat disimpulkan sebagai berikut: (1) minat dan motivasi mitra PKM cukup tinggi atau antusias untuk mengikuti seluruh kegiatan yang diberikan oleh tim pelaksana kegiatan PKM, (2) mitra PKM telah memiliki pengetahuan dan keterampilan yang memadai untuk meningkatkan kuantitas produk dengan memanfaatkan roll bending machine, (3) mitra PKM telah memiliki pengetahuan dan keterampilan yang memadai untuk meningkatkan kualitas produk.

\section{DAFTAR RUJUKAN}

Apriliyanto, E. (2020). Pemberdayaan Kelompok Wanita Tani Melalui Transfer Teknologi Pengendalian Organisme Pengganggu Tanaman Ramah Lingkungan. E-Dimas: Jurnal Pengabdian Kepada Masyarakat, 11(1), 101. https://doi.org/10.26877/e-dimas.v11i1.2817

Atmajayani, R. D. (2018). Implementasi Penggunaan Aplikasi AutoCAD dalam Meningkatkan Kompetensi Dasar Menggambar teknik bagi Masyarakat. Briliant: Jurnal Riset Dan Konseptual, 3(2), 184. https://doi.org/10.28926/briliant.v3i2.174

Badan Pusat Statistik, K. T. (2018). Temanggung dalam Angka Tahun 2018. Temanggung.

Kripsphianti, Y. D., Setyaputri, N. Y., \& Muzaki, M. F. (2019). Penggunaan Focus Group Discussion (FGD) dengan Proses Ground, Understand, Revise, And Use (Guru) Terhadap Efikasi Diri Karier Mahasiswa. In Prosiding Seminar Nasional \& Call Paper Psikologi Pendidikan 2019. Malang: Fakultas Pendidikan Psikologi Universitas Muhammadiyah Malang. Retrieved from http://ejournal.umm.ac.id/index.php/keperawatan/issue/view

Pemerintah Daerah, K. T. (2018). Laporan Kinerja Instansi Pemerintah Kabupaten Temanggung Tahun 2018. Temanggung.

Prayoga, B. T. (2015). Springback pada Pembentukan Plat Baja dengan Air Vee Bending. In Seminar Nasional Perkembangan Riset dan Teknologi di Bidang Industri (pp. 5-10). https://doi.org/10.13140/RG.2.1.4724.7201

Sonawan, H. (2014). Perancangan elemen mesin. Bandung: Alfa Media.

Widodo, L., Ariyanti, S., \& Kurniawan, F. A. (2019). Perancangan Stasiun Kerja Ergonomis Pada Stasiun Kerja Printing CV. Karyamitra Lestari. Jurnal Ilmiah Teknik Industri, 6(1), 29-34. https://doi.org/10.24912/jitiuntar.v6i1.3021

Zakaria, Z. (2018). Modifikasi Konsep Participatory Rural Apraisal Untuk Pembekalan Kuliah Kerja Nyata Mahasiswa Di Jawa Barat, Indonesia. Dharmakarya, 7(1). https://doi.org/10.24198/dharmakarya.v7i1.14592 